\title{
Designing an intersectional interventions model for brucellosis occurrence reduction in north-west of Iran
}

\author{
Damari B, MD-PhD ${ }^{1}$, Ahmadpour M, MSc ${ }^{2 *}$, Hallajzadeh J, $\mathrm{PhD}^{3}$, Hosseini SH, MSc ${ }^{4}$, Safiri S, \\ $\mathrm{PhD}^{5}$, Ghaderpoori M, MSc ${ }^{6}$, Hashemi V, $\mathrm{MSc}^{7}$
}

1- Assistant Prof., National Institute for Health Research, Tehran University of Medical Sciences, Tehran, Iran. 2-Faculty Member, Dept. of Public Health, Maragheh University of Medical Sciences, Maragheh, Iran.3-Assistant Prof., Dept. of Basic Sciences, Maragheh University of Medical Sciences, Maragheh, Iran.4-Faculty member, Vector-borne Diseases Research Center, North Khorasan University of Medical Sciences, Bojnurd, Iran. 5-PhD in Epidemiology, Road Traffic Injury Research Center, Dept. of Statistics \& Epidemiology, School of Public Health, Tabriz University of Medical Sciences, Tabriz, Iran. 6- Student of PhD, Student Research Office, Dept. of Environmental Health Engineering, School of Public Health ,Shahid Beheshti University of Medical Sciences, Tehran, Iran. PhD in Environmental Health, Faculty of Health, Shahid Beheshti University of Medical Sciences, Tehran, Iran. 7- Faculty Member, Dept. of |Basic Sciences, Maragheh University of Medical Sciences, Maragheh, Iran.

\begin{abstract}
Received: July 2015, Accepted: August 2015

Background: Brucellosis is a bacterial infection mostly transmitted by animals to humans; thus, consideration of sanitary instances is an important preventive method for this disease. Therefore, we designed a study in order to reduce the rate of brucellosis in Baneh County, Kurdistan Province, Iran.

Materials and Methods: The sources of data were the medical documents of patients diagnosed in health centers and private laboratories during 2011-2012. Data were analyzed using SPSS software, and chi-square and t-test $(\mathrm{P}<0.05)$. In addition, in the second section of the research, data on all brucellosis patients and experts were used to design an intersectional preventive interventions model for this county.

Results: A total of 135 brucellosis patients were surveyed in this study during 2011-2012, and a total of 80 experts participated in this research. It was found that 43 patients $(31.9 \%)$ lived in the city and 92 of them (68.1\%) lived in a village; and 71 of them (52\%) were men and $64(48 \%)$ were women. The most common way of incurring the disease was drinking non-boiled milk [42 $(31.11 \%)]$. Moreover, $100 \%$ of the patients and $100 \%$ of the experts believed that intersectional intervention is the best prevention method for brucellosis.

Conclusions: Considering the results, it can be concluded that the intersectional intervention with unique management is the best way for reducing the incidence and prevalence rate of brucellosisin in Baneh County.
\end{abstract}

Keywords: Epidemiological Study, Brucellosis, Malta Fever, Iran.

\section{Introduction}

Brucellosis is a bacterial zoonotic infection mostly transmitted by animals to humans. It is not transmitted from one human to another, but is a life threatening infection which represents a wide range of clinical diseases in humans mainly caused by brucella melitensisabortus (1-3). Brucellosis was discovered by David Bruce, a Scottish physician, in 1887, and due to the observation of its first case in Malta Island, it has also been named Malta fever (2-4). In many countries, brucellosis included of reportable diseases. Overall, this disease has unfavorable effects on human and animal health and their products. In animals, this disease is called fetus abortion $(3,5)$. This disease has other names like Billowy fever, Mediterranean fever, and mad fever. Human

\footnotetext{
Corresponding author: Mohammad Ahmadpour, Dept. of Public Health, Maragheh University of Medical Sciences, Maragheh, Iran.

Email: moahmadpour@yahoo.com
} 
brucellosis, Malta fever, is a serious public health risk in regions with infectious mutton and goats and seen mostly in spring and summer, the seasons of offspring and suckling of animals (5-7). There are various methods for controlling this disease which are mainly based on prevention. Therefore, surveillance is a key means of management of control, and prevention programs for this disease. Thus, consideration of sanitary instances is an important method for its prevention, and the background of this disease shows that different sectors should be responsible for its incidence and prevalence rate reduction. Based on the official data from the Ministry of Health, Treatment, and Medical Education of Iran, the morbidity rate of brucellosis in Iran, and Baneh County (Kurdistan Province, Iran), respectively, were 11635,354 and 28 cases in 2010 and 14128,536 and 65 cases in 2011. Hence, this data shows that the prevalence rate of brucellosis disease has had an ascending trend in the abovementioned places (7-9). Therefore, the present research was designed to conduct an epidemiological survey and to design an intersectional interventions model for incidence and prevalence rate reduction of brucellosis in Baneh County during 20112012.

\section{Material and Methods}

This cross-sectional and analytical study is based on several data sources such as all documents in health center and private laboratories in Baneh County and its districts. In addition, a valid and unique questionnaire was used for gathering data. The total number of brucellosis patients surveyed during 20112012 in this research was 135 cases. Moreover, the total number of experts who participated in this research was 80 individuals. The demographic and laboratory information of all cases diagnosed during 2011-2012 were studied. These patients were diagnosed using pathological tests in health care centers or private medical centers. Finally, all patients were categorized using a questionnaire based on age, gender, residential area, literacy level, job, the kind of dairy products consumed by the patient, and etcetera. Then, SPSS software (version 19, SPSS Inc., Chicago, IL, USA) and descriptive analysis, chi-square, and t-test were used for the statistical analysis of the cases $(\mathrm{P}<0.05)$. In the second section of the research, the demographic, and viewpoints of all brucellosis patients and experts were collected in order to design an intersectional interventions model to prevent the incidence of and reduce the prevalence rate of brucellosis. In this study, face-to-face and cumulative interviews were performed based on a questionnaire with all experts and patients in Baneh County. Then, through the aggregation of all of this data, an intersectional interventions model was designed. All patients and experts were free to participate in or leave the study. All participants remained in the study.

\section{Results}

The demographic data provided in table 1 show that 43 and 92 patients lived in the city and villages, respectively. In addition, $52 \%$ of them were men and $48 \%$ were women.

The results presented in table 2 illustrate that the most common cause of incurring the disease was drinking non-boiled milk. Furthermore, the majority of cases of morbidity occurred in spring and the lowest rate of morbidity was observed in winter. In addition, $34.07 \%$ of patients were ranchers.

Table 1: Frequency distribution of cases with brucellosis in Baneh County according to gender and residential area during 2011-2012

\begin{tabular}{ccccccc}
\hline \multirow{2}{*}{ Gender } & \multicolumn{2}{c}{ Women } & \multicolumn{2}{c}{ Men } & \multicolumn{2}{c}{ Total } \\
\cline { 2 - 7 } Residential area & $\mathbf{N}$ & $\mathbf{\%}$ & $\mathbf{N}$ & $\boldsymbol{\%}$ & $\mathbf{N}$ & $\boldsymbol{\%}$ \\
\hline Village & 44 & 68.75 & 48 & 67.60 & 92 & 68.10 \\
\hline City & 20 & 31.25 & 23 & 32.39 & 43 & 31.90 \\
\hline
\end{tabular}


Table 2: Occupational, seasonal, and causal distribution of cases with brucellosis in Baneh County during 2011-2012

\begin{tabular}{|c|c|c|}
\hline \multirow{6}{*}{$\begin{array}{c}\text { The Kind of consumed } \\
\text { dairy }\end{array}$} & Variable & Number (Percentage) of patients \\
\hline & Nonpasteurized ice-cream & $3(2.22)$ \\
\hline & Fresh cheese & $36(26.66)$ \\
\hline & Non-boiled milk & $42(31.11)$ \\
\hline & Fresh cheese and non-boiled milk & $28(21.59)$ \\
\hline & Others & $26(19.25)$ \\
\hline \multirow{4}{*}{ Season } & Spring & $60(44.40)$ \\
\hline & Summer & $36(26.60)$ \\
\hline & Autumn & $24(17.70)$ \\
\hline & Winter & $15(11.10)$ \\
\hline \multirow{3}{*}{$\begin{array}{l}\text { Antecedent of contact } \\
\text { with the brucellosis } \\
\text { during the last year }\end{array}$} & Yes & $97(72.30)$ \\
\hline & No & $17(12.30)$ \\
\hline & Not clear & $21(15.40)$ \\
\hline \multirow{2}{*}{ Year } & 2011 & $65(48.20)$ \\
\hline & 2012 & $70(51.80)$ \\
\hline \multirow{9}{*}{ Job } & Employee & $2(1.48)$ \\
\hline & Farmer & $17(12.59)$ \\
\hline & Self-employed & $5(3.70)$ \\
\hline & Householder wife & $20(20.74)$ \\
\hline & Rancher & $46(34.07)$ \\
\hline & Student & $20(14.81)$ \\
\hline & Labor & $8(5.92)$ \\
\hline & Others & $9(6.60)$ \\
\hline & Total & $135(100)$ \\
\hline
\end{tabular}

Table 3 shows that $86.7 \%$ of patients selected the option of "intersectional cooperation under unique management" as the best preventive model for brucellosis.
As table 4 shows, all experts were unanimous in selecting intersectional cooperation as the best method for prevention of brucellosis.

Table 3: Frequency distribution of brucellosis patients based on their viewpoints about brucellosis prevention and intersectional cooperation in Baneh County during 2011-2012

\begin{tabular}{cccc}
\hline Prevention Method & Number (Percentage) & $\begin{array}{l}\text { Organs responsible for } \\
\text { brucellosis prevention }\end{array}$ & Number (Percentage) \\
\hline Self-centered way & $4(3.0)$ & Veterinary Office & $60(44.6)$ \\
\hline $\begin{array}{c}\text { Intersectional cooperation } \\
\text { under unique management }\end{array}$ & $117(86.7)$ & Agricultural Jihad Office & $37(27.3)$ \\
\hline Other & $0(0)$ & Health Network Office & $33(24.1)$ \\
\hline No idea & $14(10.4)$ & None of them & $5(4.0)$ \\
\hline Total & $135(100)$ & Total & $135(100)$ \\
\hline
\end{tabular}

The model was derived in the final step from this research (The model of section $1 \&$ The model of section2) explains that the intersectional intervention with unique management is the best way for reducing the incidence and prevalence rate of brucellosisin in Baneh County. 
Table 4: Frequency distribution of experts based on their viewpoints about intersectional cooperation items for Brucellosis prevention in Baneh County

\begin{tabular}{cc}
\hline $\begin{array}{c}\text { Intersectional cooperation items which are necessary for Brucellosis } \\
\text { prevention }\end{array}$ & Number (Percentage) \\
\hline Determination of the Executive Committee with the cooperation of all offices & $80(100)$ \\
\hline Activation of the Executive Committee under the Governorship office & $80(100)$ \\
\hline Determination of the job description for all offices cooperated & $80(100)$ \\
\hline Compelling of all cooperating offices to execute the related affairs & $80(100)$ \\
\hline $\begin{array}{c}\text { Determination of the Educational Committee by all offices for the education of } \\
\text { target groups and the public }\end{array}$ & $80(100)$ \\
\hline
\end{tabular}

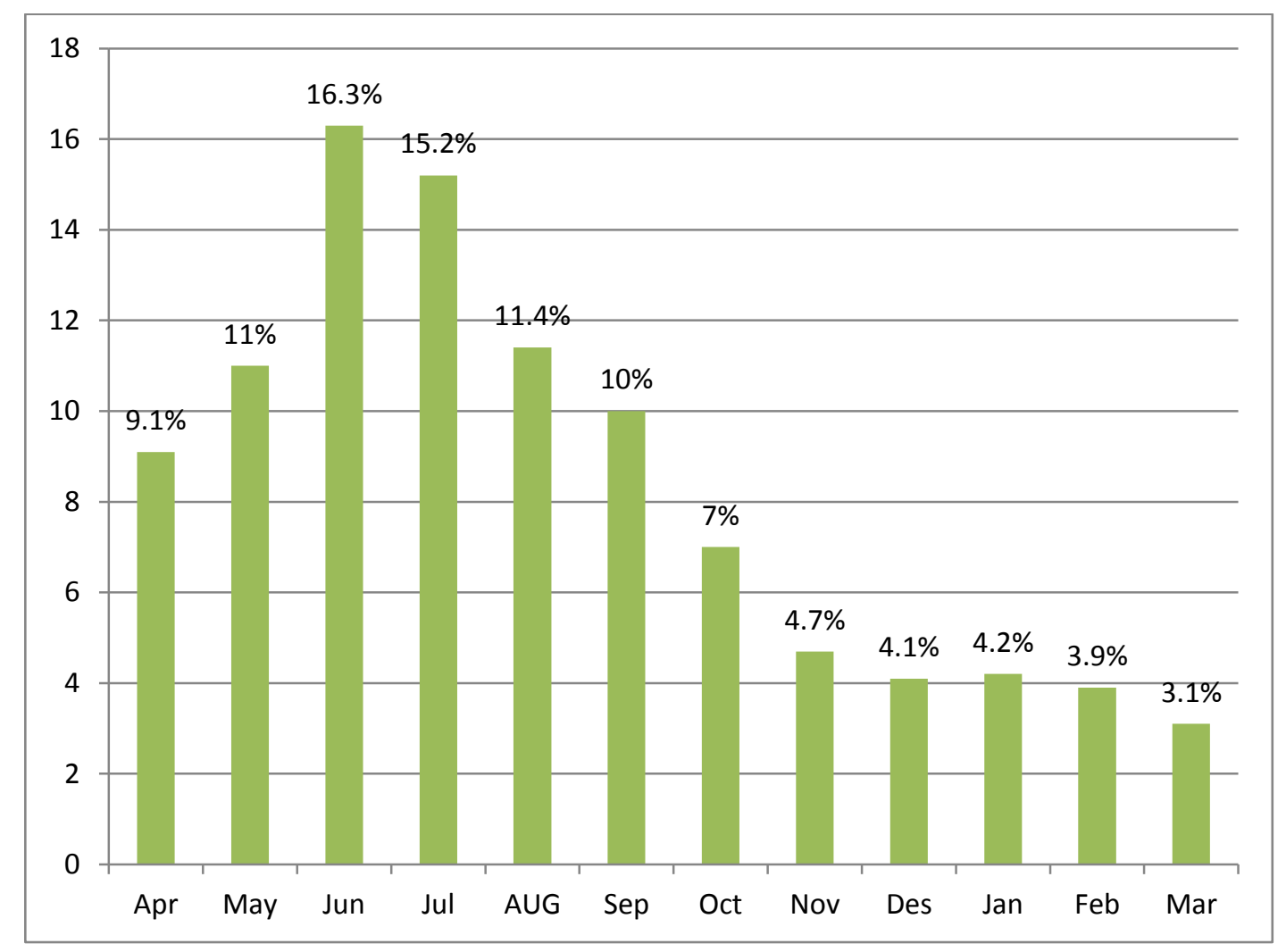

Figure 1: Monthly distribution of cases with brucellosis in Baneh County during 2011-2012

The model of section 1: The intersectional interventions model for prevention of brucellosis disease in Baneh County

Administrative structure of the model:
Inviting offices which perform actions relevant to the
prevention of brucellosis, including the Governorship Office,
Health network Office, Veterinary Office, Agricultural Jihad
Office, and Municipal Office.
Explaining the subject at the meeting with the governor and
obtaining the signature of the relevant departments
obtaining approval for projects
Formation of the Common Committee for prevention of and
fight against brucellosis in Baneh County by the related
departments
Formation of the Education Committee with the participation
of experts from relevant departments
Production and distribution of a CD and other publications with
the subject of brucellosis prevention
Taking advantage of the potential of public participation,
NGOs, and city and village councils to prevent the incidence

The Resources needed:

Human resources

Financial resources

Equipment resources

Information resources

The final outcome:

Reduction of the incidence and prevalence rate of brucellosis in Baneh County

The standard of the final outcome:

At least $20 \%$ reduction in incidence and prevalence rate of brucellosis compared to 2012 in Baneh County

\section{Costs:}

The cost of each of the study stages will be provided by Kurdistan University of Medical Sciences and the Joint Chiefs of prevention and fight against brucellosis in the 
and reduce the prevalence rate of brucellosis disease in Baneh

city of Baneh.

County

8- Preparation and codification of the program for the

prevention and treatment of brucellosis and follow-up by the

Common Committee

9- Implementation of the specified tasks by relevant

departments

Execution time :

From August 2013 for one year and renewed if necessary

10- Formation of the Monitoring and Evaluation Committee by

the relevant departments

11- Delivery of the monthly report on the progress of the

project by the Monitoring and Evaluation Committee

End users and stakeholders:

Patients, their families, Veterinary Office, Agriculture

Jihad Office, Health Network Office, and the public.

The model of section 2: The intersectional interventions model for prevention of brucellosis disease in Baneh County

Duties related to the model were approved for the related offices.

\begin{tabular}{lc} 
Description of tasks for the prevention of brucellosis for the related offices in Baneh County & $\begin{array}{c}\text { The Name of the } \\
\text { related offices }\end{array}$ \\
\hline 1-Monitoring the implementation of the tasks set for the relevant departments & Governorship Office \\
2-Coordinating relevant departments to carry out their respective duties & 3-Monitoring quarterly report measures \\
1-Supervision of the production and distribution places of dairy products and ice cream each \\
year, 20\% increase in rates compared to last year, and delivery of the quarterly report of \\
actions to the Committee for the prevention of brucellosis \\
2-Education and empowerment the people to prevent brucellosis disease and provide a 20\% \\
reduction in its prevalence compared to the previous year and delivery of the quarterly & Health Network \\
report of the actions to the Committee for the prevention of brucellosis & Office \\
3-Case detection and collection of statistical reports on patients with brucellosis, and & \\
delivery of the quarterly report of actions to the Committee for the prevention of brucellosis &
\end{tabular}

1-Planning the vaccination of animals, $20 \%$ higher than last year, and delivery of the

quarterly report of actions to the Committee for the prevention of brucellosis

2- Prevention of the activity of butchers without a permitted, $20 \%$ higher than last year, and

delivery the quarterly report of the actions to the Committee for the prevention of

brucellosis.

Veterinary Office

3-The revocation of entry and exit permits for animals in the city, 20\% higher than last year, and delivery of the quarterly report of actions to the Committee for the prevention of brucellosis

1-Monitoring the maintenance of facilities and animal husbandry, 20\% higher than last year, and delivery of the quarterly report of actions to the Committee for the prevention of

brucellosis

2-Training ranchers on health procedures of animal husbandry, $20 \%$ more than last year, and delivery of the quarterly report of actions to the Committee for the prevention of brucellosis 3-Training ranchers in the field of animal health, milk cattle, and milk transportation and distribution to health practices, $20 \%$ more than last year, and delivery of the quarterly report of actions to the Committee for the prevention of brucellosis

Agriculture Jihad Office

Monitoring of animal slaughterhouses, 20\% higher than last year, and delivery of the quarterly report to the Committee for the prevention of brucellosis

2-Monitoring of the buying and selling of cattle by local markets in the city, $20 \%$ higher than last year, and delivery of the quarterly report to the Committee for the prevention of

Municipal Office brucellosis

Intensifying security measures to prevent illegal trafficking of animals, entering or leaving the boundaries of the city to Iraq, $20 \%$ higher than in the past year, and delivery of the quarterly report to the Committee for the prevention of brucellosis

Borderline Guard Office

\section{Discussion}

The results of this study show that most cases of brucellosis were observed in 2012 and in the 2 previous years (2010-2012). Brucellosis had a fluctuating trend. A study performed in East Azerbaijan, Iran, during 8 years (3) and a 
study in Arak, Iran, during 10 years showed that the morbidity rate had fluctuated (4). This fluctuation in the morbidity rates can have several causes; for example, inaccuracy in reportage systems, some physicians in certain wards have no commitment to reporting morbidity cases to the responsible offices (5). Moreover, the quality of morbidity reports depends on the related experts following health networks of government wards.

The majority of European countries control and maintain the morbidity trend of brucellosis at a very low level in humans through surveillance systems (6). Based on official data from the Ministry of Health, Treatment, and Medical Education of Iran, the morbidity rate of brucellosis in Iran, and Baneh County were 11635,354 and 28 cases in 2010 and 14128,536 and 65 cases in 2011, respectively. This shows an ascending trend in the prevalence rate of brucellosis (7).

In this study, data were gathered from several data sources based on a valid and unique questionnaire. A total number of 135 brucellosis patients were surveyed during 2011-2012 in this research and a total number of 80 experts participated in this research. The demographic and laboratory information of all cases diagnosed during 2011-2012 were studied. $31.90 \%$ and $68.10 \%$ of patients lived in the city and villages, respectively. This result is similar to that of the epidemiological study of brucellosis in Maneh and Semelghan, North Khorasan Province, Iran, in 2008-2009 by Shoraka et al.,(8) and the epidemiological study of brucellosis in Kurdistan Province in 2006 by Esmaeilnasab et al (9). The similarity of morbidity rates in men and women in villages can be due to the similarity in jobs performed by men and women and this is also true about city residents $(9,10)$.

The incidence of brucellosis in terms of gender was different. the majority of brucellosis cases $(52 \%)$ were men, and the rest $(48 \%)$ were women. These results were similar to that of studies conducted in Oromieh, Ardabil, and Kurdistan Provinces, Iran (10). This finding shows that villagers require more educational programs.

The most common cause of the disease was drinking non-boiled milk (31.11\%). Most of the morbidity cases were observed in spring $(44.40 \%)$ and the lowest rate in winter (11.10\%) (11). Furthermore, most brucellosis patients were ranchers (34.07\%) (12). These results were similar to that obtained by Esmaeilnasab et al. and Sofizadeh et al. (13). Nevertheless, in the epidemiological studies of brucellosis by Farahani et al. in Arak, Iran, in 2001-2010 and Soleimani et al. in East Azerbaijan, Iran, in 2001-2009, the most common cause of morbidity was consuming fresh cheese (14). Moreover, these results were similar to that obtained by Brak et al. in their epidemiological study of brucellosis in Ardabil Province, Iran, in 2009 (15). This shows that in order to prevent the incidence of and reduce the rate of brucellosis more educational programs are required.

In this study, most of the patients were ranchers, which is similar to the result of a study performed in Uzbekistan (95.1\%) (16). The second highest rate of patients were homemakers $(20.74 \%)$, which is similar to the result of a study performed in Kurdistan Province (20.8\%) (8).

In this study, $44.4 \%$ of the morbidity cases occurred in spring, but in the studies conducted in Kashan city and Yazd Province, Iran, most morbidity cases had occurred in the summer $(65.5 \%)$ (17).

In the present study, $72.3 \%$ of the patients had a history of contact with an animal with brucellosis. This rate is higher than that obtained in Yazd Province (63\%), and Babol city, Iran, (54.4\%) (17).

In our study, $31.11 \%$ of the patients had consumed non-boiled (raw) milk and $21.59 \%$, both fresh cheese and non-boiled milk. However, in Babol, $58.1 \%$ of patients had consumed milk and cheese (17) and in South Khorasan Province, Iran, $30.2 \%$ of the patients had consumed milk or cheese (18).

$86.7 \%$ of the patients selected the option of "intersectional cooperation under unique 
management" as the best preventive method for brucellosis in Baneh County. An example of intersectional cooperation under unique management is all offices, the actions of which are related to the prevention of brucellosis, performing their duty within a common framework provided by the common committee.

We found $100 \%$ unanimity among experts regarding intersectional cooperation items for brucellosis reduction in Baneh County.

It can be deduced that intersectional interventions under unique management through consideration of the responsibility of all sectors is the most important way for incidence and prevalence rate reduction of brucellosis. This conclusion is similar to that reached by Mostafavi, Forghani (17), Hatami (18), and Tabatabaei in their studies (19).

\section{Conclusion}

It can be concluded that intersectional interventions under unique management through consideration of all the sectors is the most important way for incidence and prevalence rate reduction of brucellosis.

\section{Acknowledgment}

We gratefully acknowledge all experts, physicians, and patients who cooperated in this study. We sincerely thank the health personnel of Baneh Health Center for their valuable cooperation in the study.

Conflict of interest: None declared

\section{References}

1. Zeynali M, Shirzadi MR, Hajrasoliha H. National Guideline for Brucellosis Control. $2^{\text {nd }}$ ed. Guya MM, Nabavi M, eds. Tehran: Raznahan; 2011.

2. Moradi Gh, Kanani Sh, Majidpour MS, Ghaderi A. Epidemiological status survey of 3880 case of brucellosis in Kurdistan. Iranian Journal of Infectious diseases and Tropical Medicine 2006; 11(33):27-33.

3. Soleimani A, Alizadeh S, Seaif Farshad M, Kusha A, Mohamdzadeh M, Haghiri L \& et.al. Descriptive Epidemiology of Human Brucellosis in East Azerbaijan, 2001-2009. Medical Journal of Tabriz University of Medical Sciences \& Health Services 2012; 34(1):63-9.

4. Almasi-Hashiani A, Khodayari M, Eshrati B, Shamsi M. Factors affecting the interval between the onset and diagnosis of brucellosis in Markazi Province, Iran (2010-11). Arak University of Medical Sciences Journal 2012; 14(7):21-30.

5. Shoraka HR, Hosseini SH, Sofizadeh A, Avaznia A, Rajabzadeh R, Hejazi A. Epidemiological Study of brucellosis in Maneh \& Semelghan town, North Khorasan Province in 2008-2009. Journal of North Khorasan University of Medical Sciences 2010; 2(2-3):65-72.

6. Motlagh ME, Oleyaeemanesh AR, Beheshtean M. Health and social determinants of it. $2^{\text {nd }}$. Tahran: Movafagh; 2008.

7. Maleki F, RafieManesh H, AbbasiGhahramanloo A, Ghadimi N, Kousha A, Safiri S. Epidemiological characteristics of human brucellosis in Shahin Dezh, Western Azarbaijan, Iran, 2008-2012. Archives of Clinical Infectious Diseases 2015; 10(1):1-4.

8. Esmaeilnasab N, Banafshi O, Ghaderi E, Bidarpour F. Epidemiological change investigation of brucellosis in Kurdistan province in 2006-2007. J Vet Med 2007; 1(3):53-8.

9. Sofizadeh A, Ghorbani M, Salahi R, Mansorian M. Epidemiological study of brucellosis in kalaleh district, Golestan province, in 2003-2007. Journal of Research Development in Nursing \& Midwifery 2008; 5(2):8-1.

10. Mantur BG, Amarnath SK, Shinde RS. Review of clinical and laboratory features of human brucellosis. Indian J Med Microbiol 2007; 25(3):188-202.

11. Farahani Sh, Shahmohamadi S, Navidi I, Sofian M. An investigation of the epidemiology of brucellosis in Arak City, Iran 2001-2010. Arak Medical University Journal 2010; 14(6, Suppl 3):49-54.

12. Aghakhani N, saatsaz S, Sharifinia H, Soltani B, Rahbar N, Tabari F. Brucellosis epidemiology in Oromieh city. Poyesh 2012; 3:9-10.

13. Brak M, Emdadi D, Zakipor GH, Seyfnejad SH, Modaressadrdani N. Epidemiological Study of brucellosis in Ardabil Province in 2009. Paper presented at: The National Congress of Brucellosis; 2011 Sep 8-9; Arak, Iran.

14. Mahbobi S, Dorodgar A, Nematian M. Six Years Brucellosis Aspect in the district of Kashan, 2000-2005. Paper presented at: The $2^{\text {nd }}$ National Iranian Congress on Brucellosis; 2007 May 1921; Tehran, Iran.

15. Karami M, Akbarzadeh Pasha $\mathrm{H}$, Moudi S, ShaHabandaz H, Ghanbari M, Khalilpur A, et al. An epidemiologic study of brucellosis in Babylon city in 6 years. Paper presented at: The $2^{\text {nd }}$ 
National Iranian Congress on Brucellosis; 2007 May 19-21; Tehran, Iran.

16. Mostafavi E, Asmand M. Trends of Brucellosis (Malta fever) in Iran during the period 19912008. Iranian Journal of Epidemiology 2012; 8(1):94-101.

17. Earhart K, Vafakolov S, Yarmohamedova N, Michael A, Tjaden J, Soliman A. Risk factors for brucellosis in Samarqand Oblast, Uzbekistan. Int J Infect Dis 2009; 13(6):749-53.

18. Forghani H, Nezamolhoseani SM. Investigate its epidemiology of brucellosis in Yazd province, 2003- 2006. Paper presented at: The $2^{\text {nd }}$ National Iranian Congress on Brucellosis; 2007 May 1921; Tehran, Iran.

19. Hatami H. Brucellosis epidemiology. Paper presented at: The $2^{\text {nd }}$ National Iranian Congress on Brucellosis; 2007 May 19-21; Tehran, Iran.

20. Tabatabaei SM, Zahraei M, Ahmadnai H, Ghotbi M, Rahimi F. Principles of prevention and care of diseases. $2^{\text {nd }}$. Guya MM, ed. Tehran: Roohghalam; 2007. 